\title{
Pronounced effect of interannular trimethylene bridges on the rate of intramolecular electron-transfer in mixed-valence biferrocenium salts. A novel electronic ground state of ferrocenium cations
}

\author{
Teng-Yuan Dong, Ting-Yu Lee and Yuh-Sheng Wen \\ The Institute of Chemistry, Academia Sinica, Nankang, Taipei (Taiwan) \\ Shu-Hwei Lee and Chia-Feng Hsieh \\ Department of Chemistry, National Chung Hsing University, Taichung (Taiwan)
}

Gene-Hsiang Lee and Shie-Ming Peng

Department of Chemistry, National Taiwan University, Taipei (Taiwan)

(Received January 8, 1993; in revised form February 18, 1993)

\begin{abstract}
$\mathrm{X}$-ray structure determinations of two new constitutional isomers of biferrocene, the effects of interannular trimethylene bridges on intramolecular electron-transfer rates in the solid state, and characterization of the electronic ground state of a series of ferrocenium cations are reported.
\end{abstract}

Recently, there has been considerable progress in understanding the factors which control the rate of intramolecular electron transfer in the solid state for mixed-valence compounds [1-9]. The rates of electron transfer in mixed-valence cations 1-8 (Scheme 1) can be sensitively controlled by environmental factors. A recent interesting finding is that there is a significant influence on the electron-transfer rate in the mixed-valence biferrocenium salt 9 when the cyclopentadienyl (Cp) rings in each ferrocenyl moiety are linked by an interannular bridge $[8,10]$. Such a structural modification of the parallel relation between the two $\mathrm{Cp}$ rings around the $\mathrm{Fe}$ ion would lead to greater metal-ligand interactions as the rings tilt. However, there still remains one important question. At temperatures below $5 \mathrm{~K}$ compound 9 shows two doublets in the ${ }^{57} \mathrm{Fe}$ Mössbauer spectrum, one with a quadrupole splitting $\left(\Delta E_{\mathrm{Q}}\right)$ of $\sim 1.36 \mathrm{~mm} \mathrm{~s}^{-1}$ and the other with $\Delta E_{\mathrm{Q}}=\sim$ $1.88 \mathrm{~mm} \mathrm{~s}^{-1}$ [11]. There are two possible explanations for this ${ }^{57} \mathrm{Fe}$ Mössbauer spectrum. First, the Mössbauer results indicate that the valence state of iron atoms in

Correspondence to: Dr. T.-Y. Dong. compound 9 is localized on the Mössbauer time-scale $\left(10^{7} \mathrm{~s}^{-1}\right)$ in the solid state at $4.2 \mathrm{~K}$. A second possibility is that the Mössbauer sample contained both $9 a$ and
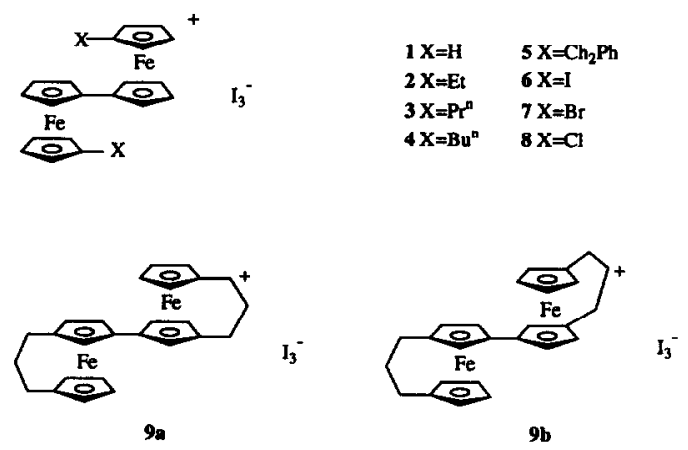

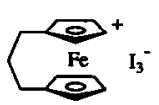

12

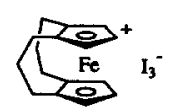

13

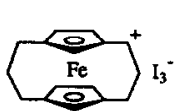

14

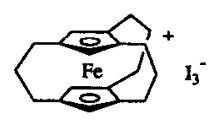

15
Scheme 1. 


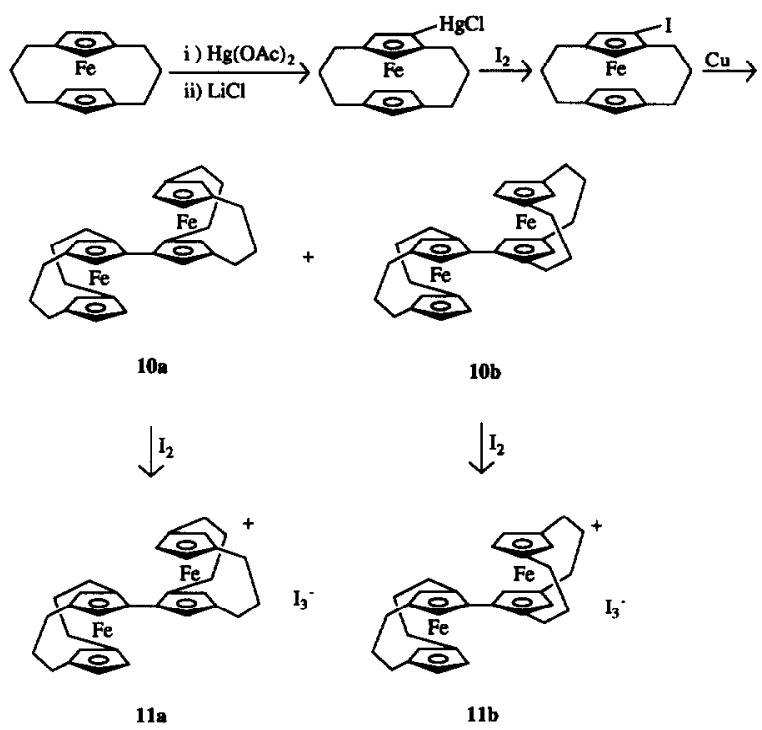

Scheme 2.

9b constitutional isomers in a $1: 1$ ratio. Unfortunately, a suitable crystal of 9 for X-ray determination could not be obtained. To study the effects of interannular bridges, we have prepared two new constitutional isomers 11a and 11b (Scheme 2), and determined the crystal structures of 10a, 10b, and 11a (see Experimental section). We now show that there is a dramatic difference in electron-transfer rates between 9 and $\mathbf{1 1}$. Additionally, the unusual physical properties of $\mathbf{1 1}$ are explained in terms of structural characteristics.

Our crystallographic study of 10a shows that there are two crystallographically independent molecules in the unit cell and one of the molecular structures is shown in Fig. 1. There are very similar geometrical arrangements in the two independent molecules. In the case of $10 \mathrm{~b}$, there are four crystallographically independent molecules in the unit cell. The average values of the dihedral angles between the two $\mathrm{Cp}$ rings of each ferrocene moiety in $10 \mathrm{a}$ and $10 \mathrm{~b}$ are $10.3(2)^{\circ}$ and $9.9(4)^{\circ}$, respectively. Furthermore, the two $\mathrm{Cp}$ rings in $10 \mathrm{a}$ and 10b are nearly eclipsed with an average staggering angle of $0.4(3)^{\circ}$ and $1.4(5)^{\circ}$, respectively. The average distances from the iron atom to the centre of mass (COM) of the Cp ring are 1.604(3) and 1.606(4) $\AA$ for 10a and 10b, respectively. These values agree well with that in ferrocene (1.65 $⿱$ ) [12]. An interesting finding is that the two $\mathrm{Cp}$ rings in the fulvalenide bridge are not coplanar. The average dihedral angles between the two $\mathrm{Cp}$ rings of the fulvalenide ligand in $10 \mathrm{a}$ and $10 \mathrm{~b}$ are $56.1(2)^{\circ}$ and $50.2(4)^{\circ}$, respectively. In the case of 1-8, a trans conformation with a planar fulvalenide bridge has been observed [3,5,9]. We believe that this difference is mainly due to the steric effect of the interannular trimethylene bridge.
As shown in Fig. 1, the cation in 11a has two dimensionally inequivalent metallocene units. The $\mathrm{Fe}^{\mathrm{II}}$ moiety in the cation has an average iron-COM distance of $1.608(6) \AA$ and the $\mathrm{Fe}^{\mathrm{III}}$ moiety has an average distance of $1.658(6) \AA$. In agreement with the Mössbauer data for 11a (vide infra), this suggests that the cation in 11a is composed of $\mathrm{Fe}^{\mathrm{II}}$ and $\mathrm{Fe}^{\mathrm{III}}$ units. The dihedral angles between the $\mathrm{Cp}$ rings associated with atoms $\mathrm{Fe} 1$ and $\mathrm{Fe} 2$ are $11.2(5)^{\circ}$ and $14.6(5)^{\circ}$, respectively. The two $\mathrm{Cp}$ rings of the $\mathrm{Fe}^{\mathrm{II}}$ and $\mathrm{Fe}^{\mathrm{III}}$ moieties are nearly eclipsed with an average staggering angle of $0.8(7)^{\circ}$ and $2.1(7)^{\circ}$, respectively. Similarly, the two $\mathrm{Cp}$ rings in the fulvalenide ligand are not coplanar, with a dihedral angle of $42.0(5)^{\circ}$. The single-crystal

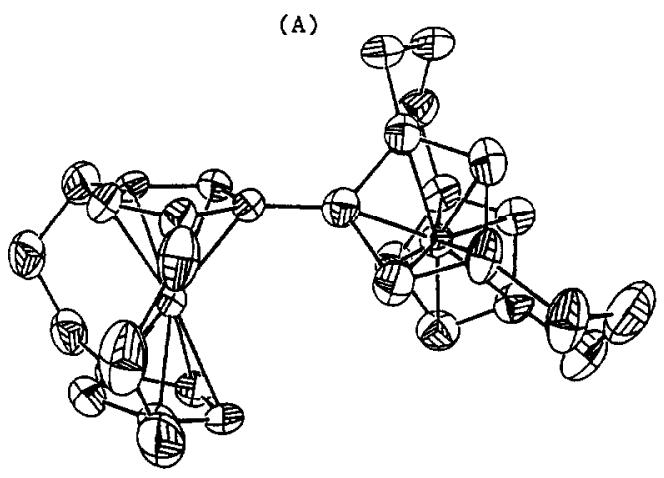

(B)
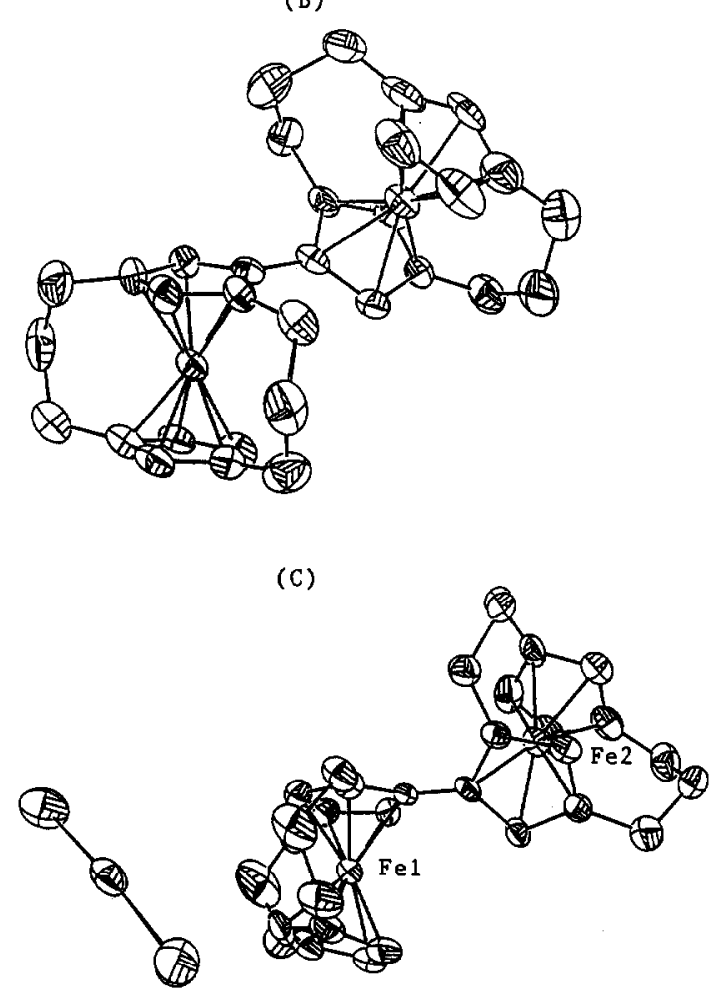

Fig. 1. Molecular structure of 10a (A), 10b (B) and 11a (C). 
(A)

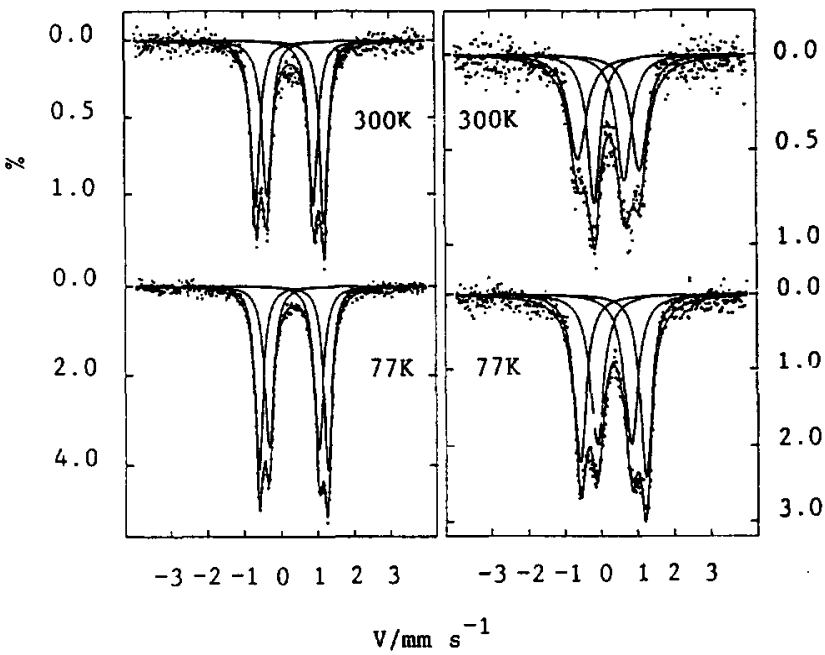

Fig. 2. ${ }^{57} \mathrm{Fe}$ Mössbauer spectra of 11a (A) and $11 \mathrm{~b}$ (B).

$\mathrm{X}$-ray determination of the structure of $11 \mathrm{a}$ indicates that this mixed-valence cation has a localized electronic state. This is also consistent with our Mössbauer results.

As shown in Fig. 2, the Mössbauer results indicate that the valence states of the iron atoms in compounds $11 \mathrm{a}$ and $11 \mathrm{~b}$ are localized on the Mössbauer time-scale $\left(10^{7} \mathrm{~s}^{-1}\right)$ in the solid state at $300 \mathrm{~K}$. At temperatures below $300 \mathrm{~K}$, the cations of $11 \mathrm{a}$ and $11 \mathrm{~b}$ show two doublets in the ${ }^{57} \mathrm{Fe}$ Mössbauer spectra, one corresponding to the $\mathrm{Fe}^{\mathrm{II}}$ and the other to the $\mathrm{Fe}^{\mathrm{III}}$ site. Thus, there is a dramatic difference in electron-transfer rates between 9 and 11. This is mainly due to the difference of coplanarity of the two $\mathrm{Cp}$ rings in the fulvalenide ligand in 9 and 11. In 11 the $\pi$ interaction between the two ferrocenyl moieties is destroyed as the linking bond of the two ferrocenyl units is twisted. From the Mössbauer studies, we can conclude that compound 9 has a localized electronic ground state at $4.2 \mathrm{~K}$ (electron-transfer rate $<10^{7} \mathrm{~s}^{-1}$ ). Of course, it is necessary to discuss why the ferrocenium moiety in 9 and 11 has an unusually large quadrupole splitting of $\sim 1.37 \mathrm{~mm} \mathrm{~s}^{-1}$. In general, ferrocenyl groups (electronic ground state ${ }^{1} \mathrm{~A}_{1_{\mathrm{g}}}$ ) give spectra characterized by large quadrupole splitting $\left(\Delta E_{\mathrm{O}}\right)$ in the range of $2.0 \sim$ $2.2 \mathrm{~mm} \mathrm{~s}^{-1}$, while the spectra of the ferrocenium cations (electronic ground state ${ }^{2} E_{2}$ ) are characterized by small or vanishing quadrupole splitting [3]. To study the influence of interannular trimethylene bridge on the electronic ground state of ferrocenium cation, we have prepared a series of model compounds 12-15 (Scheme 1). Surprisedly, a large quadrupole splitting is seen in the Mössbauer spectra of $13-15$ at $300 \mathrm{~K}$. The $\Delta E_{\mathrm{Q}}$ values of $12-15$ are $0.1484,0.9357,0.5414$, and
$0.6268 \mathrm{~mm} \mathrm{~s}^{-1}$, respectively. The Mössbauer data clearly indicate that the electronic ground state of 13-15 is not a pure ${ }^{2} \mathrm{E}_{2 \text {, }}$ state. In compounds 12-15, the $\mathrm{Cp}$ rings are tilted from the parallel geometry for ferrocenium. Bending back the $\mathrm{Cp}$ rings leads to an increase of $\mathrm{d}_{x^{2}-y^{2}}, \mathrm{~d}_{x y}$-ring overlap. In other words, the metal nonbonding orbitals start to interact with the ligand $\pi$ orbitals. Under these circumstances the iron ions lose some degree of their $\mathrm{Fe}^{\mathrm{III}}$ character, and this results in an increase in $\Delta E_{\mathrm{Q}}$ because each iron ion is closer to $\mathrm{Fe}^{\mathrm{II}}$ in its properties. This is what we observe for compounds $9,11,13,14$, and 15 .

The cation in each of the compounds 11-15 serves as a very sensitive probe of the microscopic structure of the electronic state. Characterization of the electronic ground state in these cations by magnetic susceptibility and EPR and investigation of the counteranion effects on the rate of electron transfer in solid state are underway. Studies of the electron-transfer rates of 11a and $11 \mathrm{~b}$ in the solution state and MO calculations of the theoretical values of $\Delta E_{\mathrm{Q}}$ in the cations of 11-15 are also in progress.

\section{Experimental section}

All new compounds gave satisfactory spectroscopic and analytical data. Selected physical data: 10a, m.p. $242 \sim 243^{\circ} \mathrm{C} ; \mathrm{M}^{+}, m / z \quad 530 ;{ }^{1} \mathrm{H}$ NMR $(500 \mathrm{MHz}$, $\mathrm{CDCl}_{3}$ ) $\delta 4.12$ (s, 2H, Cp), 4.07 (s, 2H, Cp), 3.79 (s, 2H, $\mathrm{Cp}$ ), 3.73 (s, 2H, Cp), 3.59 (s, 2H, Cp), and 2.2-1.4 (m, $24 \mathrm{H},-\mathrm{CH}_{2}-$ ). 10b, m.p. $192 \sim 193^{\circ} \mathrm{C} ; \mathrm{M}^{+}, \mathrm{m} / z \quad 530$; ${ }^{1} \mathrm{H}$ NMR (500 MHz, CDCl $\left.{ }_{3}\right) 83.99(\mathrm{~s}, 4 \mathrm{H}, \mathrm{Cp}), 3.82$ (s, 2H, Cp), 3.73 (s, 2H, Cp), 3.47 (s, 2H, Cp), and 2.3-1.4 $(\mathrm{m}, 24 \mathrm{H},-\mathrm{CH} 2-)$. Crystal data [298 K, Enraf-Nonius CAD-4 diffractometer, Mo $\mathrm{K} \alpha$ radiation $(\lambda=0.70930$ $\AA)$ ], no crystal decay, full-matrix least-squares refinement with $\mathrm{Fe}, \mathrm{C}$, and $\mathrm{I}$ atoms anisotropic, during the final cycles of refinement fixed hydrogen contributions with $\mathrm{C}-\mathrm{H}$ bond length fixed at $1.08 \AA .10 \mathrm{a}, \mathrm{C}_{32} \mathrm{H}_{34} \mathrm{Fe}_{2}$, $M=530.31$, triclinic, space group $P \overline{1}, a=9.1435(13)$, $b=15.0514(20), c=17.844(4) \AA, \alpha=106.39(3), \beta=$ 91.730(17), $\gamma=90.756(24)^{\circ}, U=2354.3(7) \AA^{3}, Z=4$, $D_{\mathrm{c}}=1.496 \mathrm{~g} \mathrm{~cm}^{-3}, F(000)=1112, \mu=1.25 \mathrm{~mm}^{-1}$, specimen $0.29 \times 0.28 \times 0.34 \mathrm{~mm}, 6139$ unique reflections for a $2 \theta$ limit of $44.9^{\circ}, 4458$ with $F_{o}^{2}>2.0 \sigma\left(F_{o}^{2}\right)$ used in the refinement where $\sigma\left(\mathrm{F}_{\mathrm{o}}^{2}\right)$ was estimated from counting statistics. An absorption correction was applied; $R=0.04$ and $R_{\mathrm{w}}=0.046 .10 \mathrm{~b}, \mathrm{C}_{32} \mathrm{H}_{34} \mathrm{Fe}_{2}$, $\mathbf{M}=530.31$, triclinic, space group $P 1, a=9.2089(14)$, $b=24.1318(24), c=24.501(4) \AA, \alpha=116.808(9), \beta=$ $87.980(12), y=91.577(10)^{\circ}, U=4856.2(12) \AA^{3}, Z=8$, $D_{\mathrm{c}}=1.451 \mathrm{~g} \mathrm{~cm}^{-3}, \quad F(000)=2224, \mu=1.21 \mathrm{~mm}^{-1}$, specimen $0.43 \times 0.18 \times 0.19 \mathrm{~mm}, 9860$ unique reflections for a $2 \theta$ limit of $44.9^{\circ}, 5334$ with $F_{\mathrm{o}}^{2}>2.0 \sigma\left(F_{\mathrm{o}}^{2}\right)$ 
used in the refinement. An absorption correction was made; $R=0.038$ and $R_{W}=0.041$. 11a, $\mathrm{C}_{32} \mathrm{H}_{34} \mathrm{Fe}_{2} \mathrm{I}_{3}$, $M=911.02$, monoclinic, space group $P 21 / c, a=$ 11.3628(17), $b=13.6655(15), \quad c=19.753(3) \AA, \quad \beta=$ 104.793(12), $U=2965.6(7) \AA^{3}, Z=4, D_{\mathrm{c}}=2.04 \mathrm{~g} \mathrm{~cm}^{-3}$, $F(000)=1748, \mu=4.09 \mathrm{~mm}^{-1}$, specimen $0.20 \times 0.13 \times$ $0.25 \mathrm{~mm}, 3866$ unique reflections for a $2 \theta$ limit of $44.9^{\circ}, 2296$ with $F_{o}^{2}>2.0 \sigma\left(F_{o}^{2}\right)$ used in the refinement. An absorption correction was applied; $R=0.039$ and $R_{\mathrm{w}}=0.043$.

\section{Supplementary material available}

Tables of atomic coordinates, bond lengths and angles, thermal parameters, and structure factors for $10 \mathrm{a}$, 10b and 11a (109 pages) are available from the authors.

\section{Acknowledgment}

Our work was generously supported by the National Science Council and Academia Sinica. This is gratefully acknowledged.

\section{References}

1 D.N. Hendrickson, S.M. Oh, T.-Y. Dong, T. Kambara, M.J. Cohn and M.F. Moore, Comments Inorg. Chem., 4 (1985) 329.

2 M.J. Cohn, T.-Y. Dong, D.N. Hendrickson, S.J. Geib and A.L. Rheingold, J. Chem. Soc., Chem. Commun., (1985) 1095.

3 T.-Y. Dong, D.N. Hendrickson, K. Iwai, M.J. Cohn, S.J. Geib, A.L. Rheingold, H. Sano, I. Motoyama and S. Nakashima, J. Am. Chem. Soc., 107 (1985) 7996.

4 S. Iijima, R. Saida, I. Motoyama and H. Sano, Bull. Chem. Soc. Jpn., 54 (1981) 1375.

5 M. Konno, S. Hyodo and S. Iijima, Bull. Chem. Soc. Jpn., 55 (1982) 2327.

6 M. Kai, M. Katada and H. Sano, Chem. Lett., (1988) 1523.

7 T.-Y. Dong, C.C. Schei, T.L. Hsu, S.L. Lee and S.J. Li, Inorg. Chem., 30 (1991) 2457.

8 T.-Y. Dong and C.Y. Chou, J. Chem. Soc., Chem. Commun., (1990) 1332.

9 M. Konno and H. Sano, Bull. Chem. Soc. Jpn., 61 (1988) 1455.

10 T.-Y. Dong, T.Y. Lee and H.M. Lin, J. Organomet. Chem., 427 (1992) 101.

11 Unpublished results.

12 P. Seiler and J.D. Dunitz, Acta Crystallogr., Sect. B., 35 (1979) 1068. 